\title{
A Corpus-Based Study on the Use of the Logical Connector 'Thus' in the Academic Writing of Turkish EFL Learners
}

\author{
Serpil Uçar ${ }^{1} \&$ Ceyhun Yükselir ${ }^{2}$ \\ ${ }^{1}$ School of Foreign Languages, Osmaniye Korkut Ata University, Osmaniye, Turkey \\ ${ }^{2}$ Department of English Language and Literature, Faculty of Arts and Sciences, Osmaniye Korkut Ata University, \\ Osmaniye, Turkey \\ Correspondence: Ceyhun Yükselir, Department of English Language and Literature, Faculty of Arts and Sciences, \\ Osmaniye Korkut Ata University, Turkey. Tel: 90-505-445-1671. E-mail: ceyhunyukselir@gmail.com
}

Received: December 7, 2016 Accepted: January 7, 2017 Online Published: January 10, 2017

doi: 10.5539/elt.v10n2p64 URL: http://dx.doi.org/10.5539/elt.v10n2p64

\begin{abstract}
This research was conducted to investigate how frequently Turkish advanced learners of English use the logical connector 'thus' in their academic prose and to investigate whether it was overused, underused or misused semantically in comparison to English native speakers. The data were collected from three corpora; Corpus of Contemporary American English and 20 scientific articles of native speakers as control corpora, and 20 scientific articles of Turkish advanced EFL learners. The raw frequencies, frequencies per million words, frequencies per text and log-likelihood ratio were measured so as to compare varieties across the three corpora. The findings revealed that Turkish learners of English showed underuse in the use of the connector 'thus' in their academic prose compared to native speakers. Additionally, they did not demonstrate misuse in the use of the connector 'thus'. Nevertheless, non-native learners of English tended to use this connector in a resultative role (cause-effect relation) more frequently whereas native speakers used it in appositional and summative roles more as well as its resultative role. Furthermore, the most frequent occurrences of 'thus' have been in academic genre.
\end{abstract}

Keywords: corpus-based study, logical connector, academic prose

\section{Introduction}

Cohesion is an important principle for textuality. The notion of cohesion is a semantic relation which encompasses the connections of meaning inside the text, and it defines the text (Halliday \& Hassan, 1976, p.4). Halliday and Hassan (1976) classified five categories of cohesion; reference, substitution, ellipsis, conjunction and lexical cohesion. Among five cohesion principles, conjunctions are the main cohesive devices for different scholars.

In the literature, the use of discourse connectors is a problematic area for second and foreign language learners in academic writing. Therefore, discourse connectives have been a field of big concern, especially in the advanced level of language learning (Yeung, 2009, p. 331). Several studies have already been conducted on the corpus studies of individual connectives in order to reveal their various functions and meanings as counting the frequencies in non-native writing as compared with those in native speakers' writing (Babanoğlu, 2014; Bell, 2010; Carrió-Pastor, 2013; Casteele \& Collewaert, 2013; Leedham \& Cai, 2013; Milton \& Tsang, 1993; Yeung, 2009).

Nevertheless, the field of learning discourse connectors has still been a problematic zone for English foreign language learners. This current study, therefore, was intended to find out the occurrence and discourse patterns of use for the discourse connective 'thus' appeared in the academically written articles of non-native (Turkish) learners of English through corpus-based research compared to the academical articles written by English native speakers and COCA (Corpus of Contemporary American English).

\subsection{Review of Literature}

The term conjunction, in other words, connectors have different expressions by different researchers such as 'cohesive conjunctions' (Halliday and Hassan, 1976), 'linking adverbials' (Biber, Johansson, Leech, Conrad, and Finegan, 1999), 'logical connectors' (Quirk, Greenbaum, Leech, \& Svartvik, 1985), 'discourse connectors' (Cowan, 2008) and 'discourse connectives' (Blakemore, 2002). Connectors were classified into different 
categories semantically by many well-known researchers. Halliday and Hassan (1976) classified them into 'additive', 'adversative', 'causal' and 'temporal' types; Quirk et al. (1985) classified them into 'listing', 'summative', 'appositional', 'resultative', 'inferential', 'contrastive' and 'transitional' classes. Then, Biber et al. (1999) distinguished six general semantic categories; 'enumeration and addition', 'summation', 'apposition', 'result/inference', 'contrast/concession', and 'transition' categories. Table 1 demonstrates the taxonomies of connectors classified by Quirk et al. (1985).

Table 1. Classification of Logical connectors (Quirk et al., 1985, pp. 634-636)

Classification of Logical Connectors

connectors

Listing first, second, third, firstly, secondly, thirdly, in the first place, in the second place, first of all, second of all, for one thing, to begin with, finally, lastly, last of all, equally, likewise, similarly, further, furthermore, in addition etc.

Summative altogether, overall, then, therefore, thus, all in all, in conclusion, in sum, to sum up, etc.

Appositional namely, thus, in other words, for example, for instance, that is to say, specifically, etc.

Resultative accordingly, consequently, hence, so, therefore, thus, as a consequence, in consequence, as a result etc.

Inferential else, otherwise, then, in other words, in that case etc.

Contrastive in other words, on the other hand,conversely, instead, oppositely, on the contrary, in contrast,however, nevertheless, still, though, yet, beside etc.

Transitional incidentally, by the way, meanwhile, meantime, eventually, originally, subsequently, etc.

The logical connector 'thus' has been involved in the taxonomies of 'summative', 'appositional', and 'resultative' types according to Quirk et al. (1985) as summative conjunctions describes an item that embraces all the items before; appositional conjunctions explain the preceding items in other ways; and resultative type of conjunctions tend to have a conclusion such as a summary or inference.(pp. 637-638). However, the connector 'thus' has also been distinguished as a resultative linking adverbial by Biber et al. (1999) and a cohesive causal conjunction by Halliday and Hassan (1976).

There have been some comparative studies in terms of the use of connectors in texts of native and non-native English speakers in order to analyze them syntactically and semantically, and the patterns of use, 'misuse', 'underuse' or 'overuse' of connectors analyzing corpus and constructed examples made by native and non-native learners of English (Babanoğlu, 2014; Bell, 2010; Carrió-Pastor, 2013; Casteele \& Collewaert, 2013; Leedham \& Cai, 2013; Milton \& Tsang, 1993; Yeung, 2009). Most of these studies demonstrated that there has been a higher frequency of overuse of the certain discourse connectors in the academic prose of non-native learners of English compared to native English speakers (Babanoğlu, 2014; Leedham \& Cai, 2013; Milton \& Tsang, 1993; Yeung, 2009).

As for the definition of the connector 'thus', most dictionaries (Longman Dictionary of Contemporary English, 2003; Metro Collins Cobuild Essential English-Turkish Dictionary, 1994; Oxford Advanced Learner's Dictionary, 2000) give two definitions; 'as a result of something just mentioned' as a first definition and 'in this manner or way' as a second definition. It is also used as 'thus far' like an idiom as the meaning of 'until now or up to this point'.

Nevertheless, the classifications of well-known researchers and definitions of the connective cannot explain the semantic property and syntactic positioning of the logical connector 'thus' or its register of use. Therefore, this current study makes an attempt to answer the research questions below:

1) How frequently the discourse connector "thus" appear in the academically published articles of advanced native and non-native writers (Turkish) )and in the control corpus, COCA (Corpus of Contemporary American English)?

2) Is the discourse connector "thus" overused, underused or misused semantically in the advanced published articles of non-native writers ((Turkish) compared to advanced articles of native speakers of English and COCA? 


\section{Methodology}

\subsection{Experts' Corpora}

The study was conducted with two English native speakers' corpora; the first one was Corpus of Contemporary American English (COCA) including 91,066,191 running words in academic genre and the second corpus was made up of 20 scientific articles written by English native speakers in the discipline of theoretical and applied linguistic field (273.560 running words). The scientific articles were gathered from three distinguished journals; Journal of Pragmatics, Lingua, and Cognition.

\subsection{Learner's Corpora}

The samples which compose the learner corpora were gathered from 20 scientific articles (published between 2005-2015) of Turkish non-native English speakers in the discipline of applied and theoretical linguistics (257.848 running words). The scientific articles were collected from the four distinguished journals: Journal of Pragmatics, Lingua, System and Journal of Second Language Writing. The criteria used to collect the learner and control corpora were the particular areas of linguistics and the native language of writers. Table 2 demonstrates the quantity of running words and scientific articles used in learner and control corpora.

Table 2. Number of words and articles in Learner and Control Corpora

\begin{tabular}{llll}
\hline & Learner Corpus & Control Corpora & \\
\cline { 2 - 4 } & NNES & NES & COCA \\
\hline Number of words & 257.848 & 273.560 & $91,066,191$ \\
Number of scientific articles & 20 & 20 & - \\
\hline
\end{tabular}

After the collection of scientific articles, all tables, references, figures and charts were removed from the texts so as to prepare them for analysis. After that, the taxonomies of Quirk et al. (1985) were used by the researchers since the classification was more suitable for analyzing the logical connector, "thus". Furthermore, the comparisons were made between learners' and experts' corpora to find out differences, frequencies and discourse patterns of usage of the logical connector, "thus".

\section{Results}

\subsection{Overall Frequencies across the Corpora}

\subsubsection{Corpus of Contemporary English (COCA)}

First of all, the raw frequencies of the logical connector 'thus' was counted in the Corpus of Contemporary American English (COCA) as one of the control corpora. As shown in the Table 3, the data from the corpus provide clues to the genre in which the logical connector 'thus' most frequently occurs:

Table 3. The logical connector 'thus'; frequency of occurrence and tokens per million words

\begin{tabular}{lllll}
\hline & Corpus Size & $\begin{array}{l}\text { Raw Frequency } \\
(\mathrm{rf})\end{array}$ & $\begin{array}{l}\text { Frequency } \\
\text { words } \\
(\mathrm{pmw})\end{array}$ & \\
\hline Academic & $91,066,191$ & 44.511 & 488.78 & \\
Magazine & $95,558,725$ & 9678 & 101.28 & \\
Newspaper & $91,717,452$ & 3986 & 43.46 & \\
Fiction & $90,429,400$ & 3281 & 36.28 & \\
Spoken & $95,565,075$ & 1308 & 13.69 & \\
Total & & 62.764 & 135.17 & \\
\hline
\end{tabular}

The most frequent usages of 'thus' have been in academic genre (488.78 per million words) and the least frequent one has been in spoken genre (13.69 per million words). In conclusion, Table 3 demonstrates that there is a significant difference between academic and non-academic genres in terms of the frequency of 'thus'. 
Figure 1 demonstrates the detailed distribution of the frequency of 'thus' in academic writing such as Geography and Social Sciences, Humanities, History, Education, Medicine, etc.

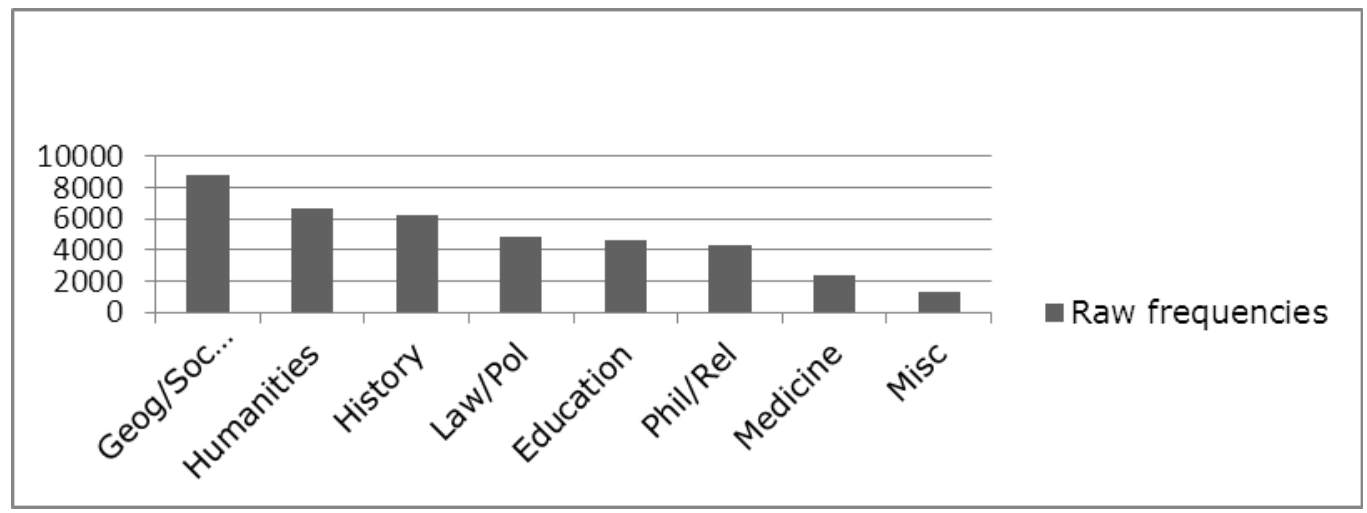

Figure 1. The raw frequencies of the logical connector 'thus' in academic writing

It can be concluded that the logical connector 'thus' is most frequently used in Geography and Social Sciences in academic writing (8802 usages), and least commonly used in miscellaneous fields (1269 usages) in written discourse.

\subsubsection{Learners' and Experts' Corpora (Native \& Non-native Scientific Articles)}

The occurrences of the connector 'thus' were counted in the scientific articles of English native and non-native Turkish writers and the findings were compared to each other. Table 4 shows the raw frequencies and frequencies per million words for the connector 'thus'.

Table 4. Raw frequencies and frequencies per million words for 'thus' in the learner and control corpora

\begin{tabular}{|c|c|c|c|c|c|c|c|}
\hline & \multicolumn{4}{|c|}{ Learner Corpus } & \multicolumn{3}{|c|}{ Control Corpus } \\
\hline & $\begin{array}{l}\text { Raw } \\
\text { Frequency }\end{array}$ & $\begin{array}{l}\text { Frequency } \\
\text { million word }\end{array}$ & per & $\begin{array}{l}\text { Frequency } \\
\text { per text }\end{array}$ & $\begin{array}{l}\text { Raw } \\
\text { Frequency }\end{array}$ & $\begin{array}{l}\text { Frequency per } \\
\text { million word }\end{array}$ & $\begin{array}{l}\text { Frequency } \\
\text { per text }\end{array}$ \\
\hline Thus & 209 & 843 & & 10.45 & 345 & 1261 & 17.25 \\
\hline
\end{tabular}

As shown in Table 4, English native speakers used the connector 'thus' more often (1261 occurrences per million words) than the non-native writers (Turkish) (843 occurrences per million words). Results demonstrated that native professional writers employed this connector an average of 17.25 per text in their academic writing while non-native writers (Turkish) used it an average of 10.45 per text in their written discourse.

\subsubsection{Log-likelihood ratio in the Use of the Connector 'Thus'}

Log-likelihood Ratio was conducted in order to reveal whether there was a marked difference between the learner and control corpora. Table 5 demonstrates the LL measurement for the frequency of the connector 'thus' between the two corpora.

Table 5. Log-Likelihood ratio (LL) of the frequency of the connector 'thus' between the learner and native corpora

\begin{tabular}{llllll}
\hline & $\mathrm{O} 1$ & $\%$ & $\mathrm{O} 2$ & $\%$ & LL \\
\hline Thus & 209 & 0.08 & 345 & $0.13-$ & 26.17 \\
\hline
\end{tabular}

$\mathrm{p}<0.001$ (critical value: 26.17); $\mathrm{O} 1$ is observed frequency in the learner corpus; $\mathrm{O} 2$ is the observed frequency in the native corpus; + indicates overuse in the learner corpus relative to the native corpus; - indicates underuse in the learner corpus relative to native corpus. 
The findings indicated that there is a statistically significant difference between Turkish non-native speakers of English and English native speakers in terms of using the logical connector 'thus' in their academic writing ( $L L=26.17$ ). The comparison between the learner and expert corpora revealed that Turkish learners of English showed underuse in the use of the connector 'thus' in their academic writing compared with native speakers.

\subsection{Discourse Patterns of Use}

\subsubsection{Corpus of Contemporary American English}

The corpus examples were analyzed in detail so as to reveal the functions and patterns of use of the connector 'thus'. Thus appears far more frequently used as a resultative conjunction including cause and effect relation as well as summative, appositional roles. Table 6 shows some concordance lines of the connector 'thus' taken from the academic genre in COCA. Furthermore, there are some typical examples of discourse patterns of thus below:

- "Third, the number of patients with amebic colitis was small; thus, the statistical power of the study might have been low." (Resultative / inferential role)

- "I thought Romney was the best that he has been, thus far. But I don't think this is over yet." (up to now, until now)

- "Bonferroni or Holm adjustment. 36 We handled missing data with a maximum likelihood approach, thus eliminating or reducing biases associated with missing data." (in this manner / way)

- "...that can create one image, automatically erase it, and then create another, thus generating an ongoing image sequence like the slides that make a cartoon." (Summative role)

- "Moreover, it is difficult to reverse the effects of silicone injection and, thus, should be used with caution." (Cause and effect- resultative role)

- "There were plenty of pretty daughters of utterly bankrupt, thus desperate, nobles for a wealthy man to chose from." (Appositional role)

Table 6. A screenshot from concordance lines of COCA

\begin{tabular}{|c|c|c|}
\hline Libraryf & $A B C$ & the list of 104 titles published in 2001 were assigned a rank of 104, thus counting them as ties for last place. The Spearman rank correlation coefficient of the \\
\hline Library & $A B C$ & ulate and reshelving statistics by title are not maintained. Thus removing print volumes available online appeared to be the most rational an \\
\hline LibraryResources & $A B C$ & form of page images that can be viewed online, printed, and downloaded, thus offering a workable facsimile of the printed volumes. In addition, the library would \\
\hline LibraryResources & $A B C$ & have electronic services that enable downloading metadata about bibliographic records related to scientific research, thus the interoperability of a repository of scient \\
\hline LibraryResources & $A B C$ & Cyrillic to Latin transliteration algorithm. All index entries are stored as Latin text, thus enabling the use of both scripts in searching. On the other hand, database \\
\hline LibraryResources & $A B C$ & Apache Lucene library. Query processing also includes a Cyrillic to Latin transliteration algorithm and thus enables the use of both scripts (Cyrillic and Latin) in search \\
\hline ucationTreatment & $A B C$ & education, many have defined evidence-based practice with this sense of the word practice. Ihus, within education, the term evidence-based practice is most often us \\
\hline eent & A $B$ & imea by mis of ner knowleage of relevant principie \\
\hline tment & A B & study (i.e, teach generalized play and develop an acceptable intervention package). $\underline{\text { Thus }}$, we created and administered subjective questionnaires to measure the ac \\
\hline Educatic & A $B$ & sessions \\
\hline Educationlre & A $B$ & ttings. Thus, although play provides contextually relevant opportunities for: \\
\hline EducationTreatment & $A B C$ & , descriptive praise, limit setting, and appropriate responses to challenging behaviors). $\underline{\text { Thus, the goals of the coaching were directly aligned with the group training. } \mathrm{V}}$ \\
\hline nent & $A B C$ & both the SEAM and the ASQ:SE (see Lissman et al., 2010). Thus, despite limited behavioral change on their part, parents reported fewer concerns about challenging \\
\hline ent & $A B C$ & to an application that is somewhat different from the research is always an issue. Thus \\
\hline & $A B C$ & recognize the importance of a study that is extremely relevant to the \\
\hline & & \\
\hline
\end{tabular}

\subsubsection{Turkish Non-Native Writers' Scientific Articles as a Learner Corpus}

In the learner corpus, thus appears more frequently as a resultative connector and then summative role respectively. Appositional role and the use of 'thus' as a meaning of "in this manner/ way" were rarely used in the corpus of non-native learners of English. Furthermore 'thus far' was used only once in the learner corpus as that in the native corpus as the reason might be of the scarcity of usage of 'thus far' in academic writing (941 occurences in COCA). The typical examples chosen from the corpus are as follows:

\section{Resultative Role (Cause and Effect)}

- "The assumption of this hypothesis is that all verb forms referring to the past are discourse-linked, and thus, are expected to be impaired in agrammatic aphasics" 
- "There was no difference in performance between the inferential and the reportative evidential. The data, thus, support the first hypothesis."

- "At essay level, all essays, and at paragraph level, 94\% of the paragraphs, were coherent; thus, no preference for digression was found."

- $\quad$ "However, abstract and coda categories are seen more frequently in the written mode. Thus, it is possible to say that abstract and coda categories are optional categories that occur in the personal experience narratives of some Turkish university students"

- “... learners become researchers participating in and observing the actions of language communities and thus raise their awareness of multiple audiences, purposes, rhetorical features and social conventions."

\section{Summative Role}

- "She describes it as a culture or tradition which respects privacy, approves of compromises and disapproves of dogmatism. Thus, she warns us not to rely only on theories that are based on influential languages, such as English

- $\quad$ Thus, for the purposes of the current study, we concentrated on the semantic components of evidential in Turkish."

- “...Thus, in line with Song's relevance-theoretic study on metonymy and metaphor, we will examine yu“z 'face' and 'heart/mind/desire' and idioms derived from them as cases of interpretive language use - that is, cases of metonymic and metaphorical metarepresentings of self that focus on "some property or value" and guide the " directions in which interpretation may proceed"

\section{Appositional Role}

- " "...they did not exhibit all the characteristics of an interactive discourse like everyday conversations. Thus, features like turn-taking, overlapping, question-answer pairs, and other paralinguistic activities which require interaction were not observed in the spoken data"

- "Evaluative language in narratives conveys or highlights interesting and unusual points about the story. Thus, the use of evaluative devices in both oral and written narratives makes the narrative stories more exciting, vivid and lively"

- "That is, V1 must be low and V2 must be high. The examples in (9a-b) contain the opposite order, thus neither left-to-right nor right-to-left assimilation create licit forms."

- “As examples (13) and (14) show, 'şey' in this usage is a syntactic constituent of the clause and has grammatical functions, and thus does not function as a DM."

\section{Meaning 'in this manner/way'}

- "...also functions as a nominal filler or "dummy" for a new referent, thus allowing the new information to occur in the post-verbal position in the sentence."

- "She observed a significant change in structural complexity with age, whereby 5-year-olds displayed a 'much stronger mental model of a story' (1993, p. 219) than 4-year-olds, thus confirming Eckler and Weininger's findings."

'Thus far'

- $\quad$ "canonical transitive word order as differing at least somewhat from any transitive sentences they had thus far heard."

\subsubsection{English Native Speakers' Articles as Control Corpus}

Having analyzed the control corpus elaboratively, the researcher discovered the examples of the use of resultative, summative and appositional roles as in the learner corpus. However, there were some differences between the two corpus examples. English native speakers are more likely to use 'thus' in the appositional role and meaning as 'in this way' as well as its resultative role. The reason might be that native speakers are more aware of the functions of 'thus' and they do not confine it to the only meaning and function of a resultative conjunction (cause-effect relationship).

Furthermore, the phrase of 'thus far' again used only once as it was in the learner corpus as it is not commonly used in academic writing. The typical examples chosen by the corpus are as follows: 
- $\quad$ "In terms of implicatures, conventional meaning is conceptually prior to an implicature. Thus it is essential for a sentence to have a conventional meaning before it can trigger an implicature." (Resultative)

- $\quad$ "So, as a hearer, I should recognise why you said something and any change in my beliefs should come (at least in part) from what is said. Communication is thus characterised as an active process where a speaker (or communicator) attempts to convey their belief to the hearer." (Summative)

- $\quad$ "Therefore, they should fit neatly within the logical framework: they are entirely predictable. For example, the word but generally signals a contrastive relationship between the meaning of the clauses which it separates. Thus, 'a but b' must conventionally imply that a and b are not normally compatible." (Appositional)

- "Generally, it seems to be that the CP is assumed to take on a meaning rather closer to

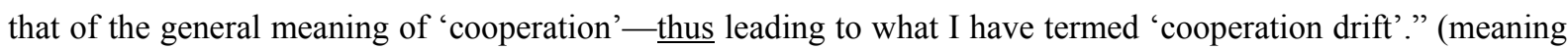
as in this way)

- "These resources are conceived of as multifunctional, in the sense that their face meaning is interpreted dynamically rather than being an inherent or fixed property. Thus, exploitation of the resources can result in various outcomes, often simultaneously." (Resultative)

- "This analysis agrees with specificational analyses that clefts are semantically parallel to specificational sentences, and thus that (i) it has semantic content (i.e., it is not an expletive), and (ii) there is a semantic modification relation between the cleft clause and it." (Appositional)

- "Grice's interests were in the system of language as an example of human rational action, and thus to be accounted for through some variety of logic." (Resultative)

- "First, it is clear that obligatory exhaustivity in specificational sentences is tied to the particular choice of surface subject. Thus, a definite subject, as in (21a), gives rise to

exhaustivity - the sentence presupposes that Mary hit no one other than Bill." (Appositional)

- "Clefts behave in a parallel fashion to specificational sentences in that the exhaustivity of the focus depends on the definiteness or otherwise of the surface subject. A specificational analysis is thus naturally equipped to handle these facts." (Summative)

- "The evidence thus far demonstrates that this particular course is Wilson's; we infer from the ranked documents and vocabulary her topical priorities."

\section{Discussion and Conclusion}

This current study was carried out so as to investigate how frequently advanced Turkish learners of English use the logical connector 'thus' in their academic prose and to investigate whether it was overused, underused or misused semantically in comparison to the native speakers of English. The learner corpus data were obtained from 20 scientific articles of distinguished international journals in the discipline of theoretical and applied linguistic field. Additionally, the expert corpora was made up of two corpora; the first corpus was Corpus of Contemporary American English (COCA) and the second control corpus was 20 native-speaker scientific articles received from the same international journals. The examples obtained from the three corpora were searched elaboratively. The raw frequencies, frequencies per million words, frequencies per text and log-likelihood ratio were measured in order to compare the differences among the three corpora (learner corpus \& expert corpora).

The findings revealed Turkish learners of English showed underuse in the use of the connector 'thus' in their academic written prose compared to native speakers. Additionally, as for the discourse patterns of usage, as Turkish learners of English were academically advanced and proficient, they did not demonstrate misuse in the use of the connector 'thus'. Nevertheless, non-native learners of English tended to use this connector in a resultative role more frequently whereas native speakers used it in appositional and summative roles as well as a resultative role and meaning 'in this way'. In addition, the most frequent occurrences of 'thus' have been in academic genre.

As for the usage of the phrase 'thus far', as it is not frequently used in academic prose, both learner and expert corpora used it only once in their academic writing. The results obtained from this current study are consistent with the previous researches that have demonstrated that the use of adverbial connectors seems to become problematic for learners because many studies reported misuse, underuse or overuse of connectors analyzing corpus and constructed examples made by native and non-native learners of English in the literature (Babanoğlu, 2014; Heino, 2010; Leedham \& Cai, 2013; Milton \& Tsang, 1993; Narita, Sato, \& Sugiura, 2004; Yeung, 2009). One of these studies was conducted by Narita, Sato and Sugiura (2004) in order to compare logical connectors in argumentative essays. The findings showed that Japanese English learners were in the tendency to use a large 
amount of additive, enumerate and appositive connectors than their native counterparts. Therefore, there have been a great amount of studies reporting underuse or overuse of connectors, which is in line with the findings of the current research.

As a conclusion, this current study has made an attempt to reveal the frequency, functions and patterns of 'thus' as a connector in all of the three corpora. Significant differences were found between expert and learner corpora. Connectors are obviously a trouble-spot not only for Turkish advanced learners but also for other learners from different linguistic backgrounds. Therefore, conventional ways of teaching and conventional theories seem to be inadequate for gaining necessary knowledge of connectors.

\section{References}

Babanoğlu, M. P. (2014). A corpus-based study on the use of pragmatic markers as speech-like features in Turkish EFL learners' argumentative essays. Procedia-Social and Behavioral Sciences, 136, 186-193. https://doi.org/10.1016/j.sbspro.2014.05.312

Bell, D. M. (2010). Nevertheless, still and yet: Concessive cancellative discourse markers. Journal of Pragmatics, 42(7), 1912-1927. https://doi.org/10.1016/j.pragma.2009.12.010

Biber, D., Johansson, S., Leech, G., Conrad, S., \& Finegan, E. (1999). Longman grammar of spoken and written English. Harlow: Pearson Education Limited

Blakemore, D. (2002). Relevance and linguistic meaning: The semantics and pragmatics of discourse markers. Cambridge: Cambridge University Press. https://doi.org/10.1017/CBO9780511486456

$\mathrm{Bu}, \mathrm{J}$. (2013). A study of the acquisition of discourse markers by Chinese learners of English. International Journal of English Studies, 13(1), 29-50.

Carrió-Pastor, M. L. (2013). A contrastive study of the variation of sentence connectors in academic English. Journal of English for Academic Purposes, 12(3), 192-202. https://doi.org/10.1016/j.jeap.2013.04.002

Casteele, A. V., \& Collewaert, K. (2013). The Use of Discourse Markers in Spanish Language Learners' Written Compositions. Procedia-Social and Behavioral Sciences, 95, 550-556. https://doi.org/10.1016/j.sbspro.2013.10.681

Cowan, R. (2008). The teacher's grammar of English with Answers: A Course Book and Reference Guide. Cambridge: Cambridge University Press.

Halliday, M. K, \& Hasan, R. (1976). Cohesion in English. London: Longman.

Heino, P. (2010). Adverbial connectors in advanced EFL learners' and native speakers'student writing. Student Thesis, University of Stockholm, Stockholm.

Leedham, M., \& Cai, G. (2013). Besides... on the other hand: Using a corpus approach to explore the influence of teaching materials on Chinese students' use of linking adverbials. Journal of Second Language Writing, 22(4), 374-389. https://doi.org/10.1016/j.jslw.2013.07.002

Lei, L. (2012). Linking adverbials in academic writing on applied linguistics by Chinese doctoral students. Journal of English for Academic Purposes, 11(3), 267-275. https://doi.org/10.1016/j.jeap.2012.05.003

Longman Dictionary of Contemporary English. (2003). Pearson Education Limited, Edinburgh Gate.

Metro Collins Cobuild Essential English-Turkish Dictionary. (1994). HarperCollins Publishers, Istanbul.

Milton J. \& Tsang E. (1993). A corpus-based study of logical connectors in EFL students' writing. In R. Pemberton, \& E. Tsang (Eds.), Studies in Lexis (pp. 215-246). Hong Kong: Hong Kong University of Science and Technology.

Narita, M., Sato, C., \& Sugiura, M. (2004). Connector usage in the English essay writing of Japanese EFL learners. Proceedings of 4th International Conference on Language Resources and Evaluation. LREC, 1171-1174.

Oxford Advanced Learner's Dictionary. (2000). 6th ed. Oxford University Press, New York.

Quirk, R., Greenbaum, S., Leech, G., \& Svartvik, J. (1985). A comprehensive grammar of the English language. London: Longman.

Yeung, L. (2009). Use and misuse of 'besides': A corpus study comparing native speakers' and learners' English. System, 37(2), 330-342. https://doi.org/10.1016/j.system.2008.11.007 
Note.

One part of this paper was presented as a proceeding in the International Classroom Practitioner's Perspective Conference held in 24-26 November 2016. This is the extended and full version.

\section{Copyrights}

Copyright for this article is retained by the author(s), with first publication rights granted to the journal.

This is an open-access article distributed under the terms and conditions of the Creative Commons Attribution license (http://creativecommons.org/licenses/by/4.0/). 